\title{
A CASE OF QUADRICUSPID AORTIC VALVE WITH AORTIC REGURGITATION
}

\section{YOUNG JIN YOUN, MD, JANG-YOUNG KIM, MD, SANG WOO HARN, MD, JUN-WON LEE, MD, JUNG-KYUNG SUNG, MD, SUNG-GYUN AHN, MD, BYUNG-SOO YOU, MD, SEUNG-HWAN LEE, MD, JUNGHAN YOON, MD AND KYUNG-HOON CHOE, MD}

DIVISION OF CARDIOLOGY, DEPARTMENT OF INTERNAL MEDICINE, WONJU COLLEGE OF MEDICINE, YONSEI UNIVERSITY, WONJU, KOREA

Quadricuspid aortic valve (QAV) is a rare form of congenital malformation. It was first described by Balington by autopsy study in 1862 . Aortic regurgitation is the predominant valvular dysfunction associated with QAV, whereas valvular stenosis is very rare. QAV may also be diagnosed as a lonely lesion without other malformation, but QAV could be asso- ciated with patent ductus arteriosus, anomalies of coronary arteries, ventricular septal defect and pulmonary artery stenosis, subaortic fibromuscular stenosis, and hypoplasia of anterior mitral leaflet. ${ }^{\left.1{ }^{2}\right)}$

A 56-year old male patient was admitted to our institute complaining of dyspnea. He had a history of hypertension,
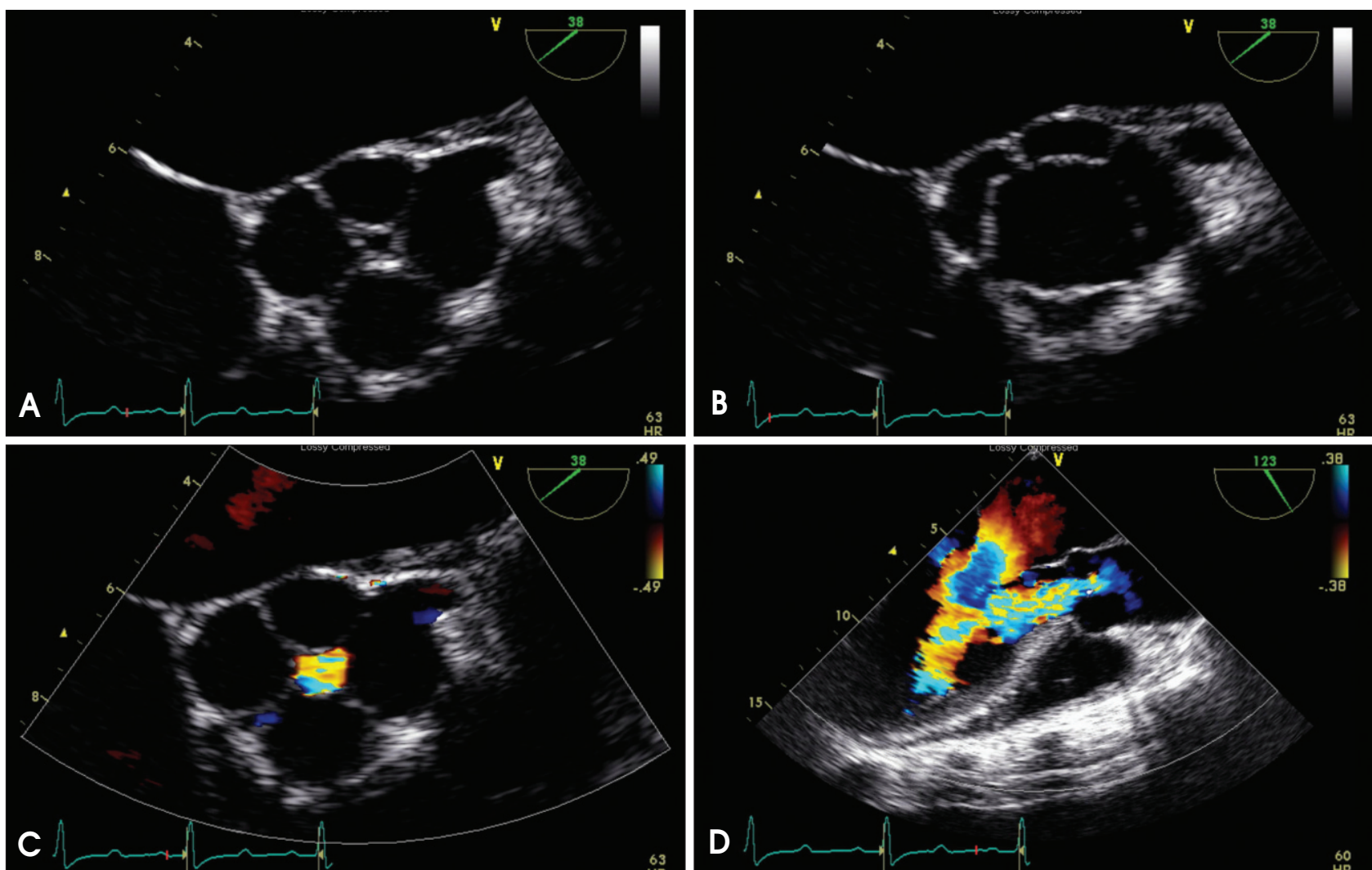

Fig. 1. Transesophageal echocardiography shows a quadricuspid aortic valve with a normal systolic opening of all 4 leaflets and the presence of incomplete central leaflet coaptation. Four cusps are of equal size. A: Diastolic frame. B: Systolic frame. C and D: Color Doppler interrogation featuring aortic regurgitation.

Received: March 19, 2010 •Revised: April 27, 2010 • Accepted: May 18, 2010

Address for Correspondence: Jang-Young Kim, Division of Cardiology, Department of Internal Medicine, Wonju College of Medicine, Yonsei University, 162 Ilsan-dong, Wonju 220-701, Korea Tel: +82-33-741-0909, Fax: +82-33-741-1219, E-mail: kimjy@yonsei.ac.kr 
diabetes mellitus, diabetic retinopathy and diabetic nephropathy. He was a chronic alcohol drinker. His vital sign was stable but initial chest X-ray showed cardiomegaly, pulmonary congestion and blunting at both costophrenic angles. Initial laboratory findings showed increased blood urea nitrogen $(97 \mathrm{mg} / \mathrm{dL})$ and creatinine level $(10.6 \mathrm{mg} / \mathrm{dL})$. With the diagnosis of aggravated chronic renal failure, he underwent emergency hemodialysis. After dialysis, he was consulted to cardiology for evaluating heart failure. Transthoracic echocardiography showed left atrial enlargement and aortic regurgitation grade II/IV at parasternal long axis view. At parasternal short axis view, aorta showed 4 cusps. Left ventricular enlargement (end-diastolic and end-systolic diameters, respectively, of 6.8 and $5.3 \mathrm{~cm}$ ) and systolic dysfunction (ejection fraction of 44\%) were also observed. Transesophageal echocardiography was performed for a detailed examination of the aortic valve and root. The examination showed a QAV (4 sinus of valsalva and 4 aortic cusp: four cusps were of equal size) with a normal systolic opening of all 4 leaflets and the presence of incomplete central leaflet coaptation (Fig. 1A and B). Color Doppler examination confirmed the existence of a central aortic regurgitation (Fig. 1C and D). No other cardiac abnormalities associated with QAV were found.

\section{REFERENCES}

1. Kang WY, Kim W, Moon Y, John SH, Choi JB, Jo SC, Jung AD, Jo YC, Hwang SH, Kim W. Two cases of quadricuspid aortic valve associated with aortic regurgitation and infective endocarditis. J Cardiovasc Ultrasound 2007; 15:131-5.

2. D’Aloia A, Vizzardi E, Bugatti S, Chiari E, Repossini A, Muneretto C, Dei Cas L. A quadricuspid aortic valve associated with severe aortic regurgitation and left ventricular systolic dysfunction. Eur J Echocardiogr 2009; 10:724-5. 